\title{
Effect of an Educational Intervention on Quality of Life and Sexual Function in Women with Endometriosis
}

\author{
Hend Abdallah EL Sayed ${ }^{1} \&$ Samia Abdel Hakeem Hanseen Aboud ${ }^{1}$ \\ ${ }^{1}$ Obstetrics and Woman Health Nursing, Faculty of Nursing, Benha University, Egypt \\ Correspondence: Hend Abdallah EL Sayed, Assistant Professor of Obstetrics and Woman Health Nursing, \\ Faculty of Nursing, Benha University, Egypt. E-mail: hend.afify@ fnur.bu.edu.eg
}

Received: July 21, 2018

Accepted: August 9, 2018

Online Published: August 16, 2018

doi:10.20849/ijsn.v3i2.452

URL: https://doi.org/10.20849/ijsn.v3i2.452

\begin{abstract}
Aim of the study was to investigate the effect of an educational intervention on quality of life and sexual function in women with endometriosis. Design: Quasi experimental time series research design. Setting: obstetrics and gynecology outpatient clinic affiliated to Benha University Hospital and Benha teaching Hospital. Sample: A purposive sample of 138 women diagnosed with endometriosis was eligible in the study and assigned equally into study and control groups. Tools for data collection: A structured interviewing questionnaire, Endometriosis Health Profile Questionnaire-30 and Sexual Health Outcomes in Women Questionnaire. Results: There was no statistically significant difference between both groups regarding demographic and obstetrical characteristics ( $\mathrm{p}$ $>$ 0.05). Before implementation of educational intervention, the mean scores of total EHP-30 and SHOW-Q showed impaired quality of life and sexual function in the both groups $(p>0.05)$. After one and two months of educational intervention implementation, mean total score of EHP-30 was significantly lowered in the study group compared with the control group. The mean scores of satisfaction, orgasm, and desire subscales were significantly higher in study group compared with control group. Whereas, the mean score of the pelvic problem interference subscale was significantly lower in study group compared with control group $(p \leq 0.001)$. Conclusion: The educational intervention about endometriosis has significant effect on the improvement of women's quality of life and sexual function. Recommendation: Provide health educational program for women with endometriosis to improve quality of life as well as sexual function.
\end{abstract}

Keywords: educational intervention, endometriosis, quality of life, sexual function

\section{Introduction}

Endometriosis is one of the most common gynecological diseases and is defined as a chronic disorder characterized by the ectopic presence of functional endometrial tissue, glands, and stroma outside the uterine cavity (Greene et al. 2016). Endometriosis affects approximately $10 \%$ of child bearing women. Endometriosis is therefore of considerable importance both directly in terms of its potentially negative impact on women affected by the condition and indirectly on healthcare systems and society (Culley et al. 2013; Ferreira et al. 2016).

Endometriosis affects women of reproductive age with various signs and symptoms as; chronic pelvic pain, infertility, dysmenorrhea, dyspareunia, abdominal pain, fatigue, sexual dysfunction, dysuria, dysphasia and loss of healthy and active body conditions (Montanari et al. 2013).

The pathogenesis of endometriosis is still unknown, and various theories have been proposed to explain it. Endometriosis has multifactorial etiology which includes: genetic predisposition, immune system abnormalities, anatomical and environmental factors (Begum and Chowdhury, 2013; Lagana et al. 2017). Endometriosis can be staged I-IV (I-minimal, II-mild, III-moderate, and IV severe) according to the American Society of Reproductive Medicine, based on; the location, extent, and depth of endometrial implants, a presence and severity of adhesions and size of ovarian endometriom (Giuliani, 2016).

Quality of life (QOL) is a multidimensional and dynamic concept that includes physical, social and mental aspects of health which is associated with a particular disease or its treatment (Silva et al. 2015). Endometriosis has an adverse impact on physical, mental, and social well-being and therefore a negative impact on health-related quality of life (Moradi et al. 2014). Quality of life and sexual function domains are considered two core aspects of human health (WHO, 2010; Peloquin et al. 2013). 
Additionally, sexual health is a critical aspect of quality of life that is influenced by medical conditions and health-care interventions, particularly gynecological disorders (Langer et al. 2015). Coital pain is a symptom reported by almost half of women suffering from endometriosis and affect sexual functioning. However, sexuality is a complex phenomenon driven by social, psychological and biological/hormonal factors and endometriosis might further affect sexual function and quality of sexual relationship. Consequently, sexual health is a major concern for women with endometriosis and should be crucial concern in endometriosis care (Pluchino et al. 2016).

Treatment options for women with endometriosis are diverse and consist of analgesics, hormonal therapy, conservative or radical surgery, assisted reproduction, or a combination of these (Dunselman et al. 2014). The aim of medical treatment is to suppress the growth and activity of endometriotic lesions. All have similar clinical efficacy in terms of reduction of pain-related symptoms and duration of relief (Bedaiwy and Liu, 2010). The aim of the surgical approach is the excision of all visible lesions to obtain a maximum effect regarding pain relief and increase fertility. However, surgery may be associated with peri- and postoperative complications and also confers recurrence of disease even in optimally resected cases (Setala et al. 2012).

Nurses play an essential role in health promotion through disease management and infertility prevention by providing support and required information to the woman with endometriosis. Nurses can also facilitate quality of care and manage treatments effectively to improve quality of life, reduce pain, and prevent further progression of disease (Mao and Anastasi, 2010). In addition, the nurse should allow time for the woman to express concerns about complaints and treatment modalities. The woman should be taught the expected effects of drugs given for endometriosis treatment precautions and adverse effects (McKinney et al. 2013).

\subsection{Significance of the Study}

Endometriosis is a complex gynecologic disease that impacts nearly 176 million women of reproductive age worldwide, or approximately 5-10\% of all ethnicities and socioeconomic backgrounds (Kong et al. 2014). In Egypt, prevalence rates are unknown, because a definitive diagnosis is established only at laparoscopy. Endometriosis is a disabling condition noticeably affects different aspects of women's daily lives, social relationships and sexual function. Therefore, there was a significant need to improve women's health-related quality of life by increasing awareness and continuous education about management of endometriosis. To the best of our knowledge, no available previous research study providing educational intervention beneficial for quality of life and sexual health for women with endometriosis. Thus, this study is conducted to investigate the effect of an educational intervention on quality of life and sexual function in women with endometriosis.

\subsection{Aim of the Research}

This study aimed to investigate the effect of an educational intervention on quality of life and sexual function in women with endometriosis.

\subsection{Research Hypothesis}

Women with endometriosis who will receive an educational intervention exhibit better quality of life and sexual function than those who don't receive it.

\section{Subject and Methods}

\subsection{Research design}

Quasi experimental time series research design was followed to fulfill the aim of the study.

\subsection{Setting}

The study was conducted in obstetrics and gynecology outpatient clinic affiliated to Benha University Hospital and Benha teaching Hospital. These particular settings were chosen because it considers the main governmental hospitals in Benha city.

\subsection{Sample}

The study comprised a purposive sample of 138 women diagnosed with endometriosis and attended in the above mentioned settings. The sample size was calculated based on the formula Kish (1965) $n=Z^{2}$ p q / e where $Z=$ 1.96; prevalence $(\mathrm{p})=10 \%$; margin of error $(\mathrm{e})=5 \%,(3.84 * 0.10 * 0.9 / 0.0025)$. The desired sample size will be 138 women. The sample were assigned equally into either study or control group.

Women were recruited according to inclusion criteria; women of reproductive age (18-45) years, diagnosed with endometriosis, married and sexually active, free from any gynecological disorder that may cause dyspareunia or 
sexual dysfunction, and who are willing to participate in the study. Exclusion criteria; women with surgical prove of endometriosis, women suffering from any chronic illness or psychological disorder.

\subsection{Tools of Data Collection}

Three tools were used for data collection.

Tool I: A structured interviewing questionnaire

This tool was developed by the researchers after reviewing related literature and consisted of four parts:

Part (1): Demographic data of the studied women included age, educational level, residence, occupation, and monthly income.

Part (2): Obstetrical history included gravidity and parity.

Part (3): Data about endometriosis included duration, stage, and types of endometriosis.

Part (4): Numerical rating scale was adopted from Posadzka et al. (2015) to assess the intensity of endometriosis-related pain symptoms as dysmenorrhea, dyspareunia, and non-menstrual pelvic pain...etc. Women asked to rate the current intensity of endometriosis-related pain symptoms where, (0) indicating no pain and (10) indicating the worst possible pain.

Tool II: Endometriosis Health Profile Questionnaire-30 (EHP-30)

The EHP-30 was adopted from Jones et al. (2001), translated into Arabic language by the researchers to assess health related quality of life in women with endometriosis during the past 4 weeks. Core questionnaire of EHP-30 is applicable to all women with endometriosis, containing 30 items in five subscales; pain (11 items), control and powerlessness (6 items), social support (4 items), emotional well-being (6 items), and self-image (3 items).

\section{Scoring System:}

Each scale of EHP-30 is standardized on a scale of 0-100, where 0 indicates the best health status through to 100 the worst health status. Scores for each scale are calculated from the total of the raw scores of each item in the scale divided by the maximum possible raw score of all the items in the scale, multiplied by 100 .

\section{Tool III: Sexual Health Outcomes in Women Questionnaire (SHOW-Q)}

The SHOW-Q was adopted from Learman et al. (2008), translated into Arabic language by the researchers to assess different aspects of sexual life and interference with sexual functioning by pelvic problems in relation to the previous 4 weeks. The SHOW-Q included 12 items for the assessment of four subscales; satisfaction (2 items), orgasm (4 items), desire ( 3 items), and pelvic problem interference (3 items).

\section{Scoring System:}

All items were scored on a scale from 0 to 100. For the first three subscales (satisfaction, orgasm, and desire), higher scores represented better sexual functioning; except the fourth subscale (pelvic problem interference), higher score indicated greater interference and represented worse sexual functioning.

\subsection{Tools Validity and Reliability}

Tools content validity was reviewed for appropriateness of items by jury panel of three experts in the field of obstetric and women health nursing and obstetric medicine. Simple modifications were done by rephrasing of some sentences according to the experts' judgment on clarity of sentences and the appropriateness of contents. The reliability was done by Cronbach's Alpha coefficient test, internal consistency of The EHP-30 equal 0.82, and The SHOW-Q equal 0.86 .

\subsection{Ethical Considerations}

An informed oral consent was obtained from enrolled women after clarifying the aim and nature of the study. Confidentiality and anonymous of collecting data were maintained. As well as respect of women's privacy was ensured. Each participant was informed that participation is voluntary and has the right to withdraw from the study at any time without affect the care provided. Moreover, the collected data were away from the moral and religious aspects of the enrolled participants. After completion of the research, an educational booklet was distributed to the control group.

\subsection{Pilot Study}

The pilot study was carried out on $10.0 \%$ of the sample 14 women ( 7 from each group) to test the applicability and clarity of the study tools, as well as estimate the time needed to fill the study tools and find out any problem 
that may interfere with the process of collecting data. According to the results of the pilot study, no modification was required. Women in the pilot study were included in the main study sample.

\subsection{Procedure}

An official permission was granted from the Dean of the Faculty of Nursing, Benha University and delivered to the directors of Benha University Hospital and Benha teaching Hospital in order to obtain approval for conduction of the research after explaining the aim. The previous mentioned settings were visited by the researchers four days/week; (Saturday and Sunday) for Benha teaching Hospital, (Tuesday and Wednesday) for Benha University Hospital from 9.00 am to 12 pm.

The following phases were adopted to fulfill the aim of the current research: assessment, planning, implementation, and evaluation. These phases were carried out from beginning of February 2017 to the end of January 2018 covering twelve months.

\subsubsection{Assessment Phase}

This phase encompassed interviewing women willing to participate in the study and met the inclusion criteria. The researchers greeted each woman at the beginning of the interview, explained the aim, duration, and activities of the study and took informed oral consent. Each woman was individually interviewed in waiting area of the outpatient clinic before or after obstetrician consultation. The questionnaires were filled by the control and study groups pretest as a baseline data for further comparisons. The average number of interviewed women per week was 6-8 women. The time needed for completing the questionnaires was 30-35 minutes for each woman.

\subsubsection{Planning Phase}

Based on the results of the assessment phase and related literature, the educational sessions and booklet about endometriosis were prepared by the researchers in simple Arabic language to suit women's level of education.

\subsubsection{Implementation Phase}

The study group: Educational intervention was conducted in four educational sessions; each lasted 30-40 minutes. At the beginning of each session, the researchers started by giving a summary about the previous session and explaining the objective of the new one. Different teaching methods were used including discussion and brainstorming. The used teaching aids were power point presentation, educational booklet and videos.

Session one comprised information about the definition, causes, pathophysiology and stages of endometriosis, symptoms and effects of endometriosis, diagnosis, medical and surgical treatment of endometriosis. In addition to future follows up.

Session two elaborated non-pharmacological management strategies for relieving endometriosis-related pain symptoms (dysmenorrhea, dyspareunia, dysuria, dysphasia, and chronic pelvic pain) such as frequent rest periods, application of heat to the lower abdominal, massage.....etc. As well as discussion of benefits of regular physical exercise which lowers body estrogen to relief endometriosis symptoms. Instruct women about proceeding exercises by walking three times per week for 15-30 minutes.

Session three comprised counseling and information about healthy diet for endometriosis as eliminate dairy foods, red meat, refined sugars, caffeine and carbohydrates. Soy and other high-estrogen foods should also be eliminated from diet. Follow an anti-inflammatory diet for example green leafy vegetables, celery, broccoli, salmon, ginger and Omga3 as well as intake of magnesium and iron rich foods.

Session four involved psychological support offered to women with endometriosis, encourage women to express their complaints, concerns and anxieties about therapy and sexual problems for assisting women in coping with symptoms associated with endometriosis. Emphasize of the importance of communication within husband relationship. Discuss of alternative and comfortable sexual positions. In addition, teach Kegel exercise to help the woman relax the pelvic floor muscles.

Moreover, women received an educational booklet at the end of the sessions. Women were permitted to communicate and ask any questions via telephone call.

The control group obtained the routine hospital care that concentrated on gynecological diagnosis and treatment without giving any more information about endometriosis.

\subsubsection{Evaluation Phase}

After one and two months of administering the educational session, follow up was done by using the same pretest tools II and III. The period of one month was chosen because most women are expected to be in the same 
period of their menstrual cycle, which may be relevant regarding endometriosis complaints. Some women were followed via telephone. Evaluation started first with control group then a study group to avoid bias.

\subsection{Statistical Design}

Collected data were tabulated and statistically analyzed using Statistical Package for the Social Science (SPSS version 20). Descriptive statistics: Mean standard deviation or frequencies and percentages. Inferential statistics: independent $t$ test was used to determine the difference between the groups and repeated measure ANOVA (F) used to determine the difference within groups. Chi-square test $\left(\chi^{2}\right)$ and Fisher Exact Test were used to study association between two qualitative variables. Pearson correlation coefficient (r) was calculated between two continuous quantitative variables. The difference was considered significant at $\mathrm{P} \leq 0.05$, and a highly significant was considered when p-value $\leq 0.001$.

\subsection{Limitations of the Study}

The educational sessions were accomplished almost individually; it spent more exertion and time. Lack of national and international studies related to the research topic.

\section{Results}

Table (1) shows that, the mean age of the study and control groups was $32.29 \pm 2.58$ (range: 27 to 41 years) and $31.54 \pm 2.91$ years (range: 26 to 45 years) respectively. Less than two thirds of both groups had a secondary education, whereas only $2.9 \%$ of the study group and $5.8 \%$ of the control group had primary education. Regarding residence, $84.1 \%$ of the study and $76.8 \%$ of the control groups live in rural areas. In relation to occupation, $55.1 \%$ and $68.1 \%$ of both study and control groups respectively were housewives. More than three quarters of both groups had no enough monthly income. There was no statistically significant difference between both groups regarding demographic characteristics $(\mathrm{p}>0.05)$.

Table (2) displays that, $71.0 \%$ and $66.7 \%$ of the study and control groups were nulligravidae respectively and $75.4 \%$ and $69.6 \%$ of the study and control groups were nulliparae respectively. Regarding type of endometriosis, $76.8 \%$ of the study and $82.6 \%$ of control group had ovarian endometriosis, $79.7 \%$ and $72.5 \%$ of the study and control groups had stage I endometriosis. The mean duration of endometriosis of the study and control groups was $3.93 \pm 0.73$ and $3.72 \pm 0.95$ years respectively. There was no statistically significant difference between both groups regarding obstetrics history and data about endometriosis $(p>0.05)$.

Figure (1) illustrates that the mean score of intensity of endometriosis-related pain symptoms (dysmenorrhea, chronic pelvic pain, dyspareunia, dyschezia and dysuria) were matched in both groups before implementation of educational intervention. Meanwhile, mean score of endometriosis-related pain symptoms remarkably reduced in the study group compared with the control group after one month and two months of educational intervention implementation.

Table (3) illustrates that, before implementation of the educational intervention, the mean scores of total EHP-30 showed impaired quality of life in the study and control groups (mean EHP-30 total score $42.52 \pm 1.59$ and 42.94 \pm 1.54 respectively), with no statistically significant difference ( $\mathrm{p}$ value $=0.118$ ). However, statistically significant differences in the mean scores were observed between the groups after one and two months of implementation of an educational intervention. The mean total score of EHP-30 was significantly lowered in the study group compared with the control group. Such significant differences also existed in the five dimensions of EHP-30; pain, control and powerlessness, emotional well-being, social support, and self-image ( $p \leq 0.001)$.

Table (4) displays that, before implementation of educational intervention, the mean scores of total SHOW-Q and its subscales in the both groups showed poor sexual function (mean SHOW-Q total score $52.58 \pm 4.45$ in the study group and $53.19 \pm 3.76$ in the control group), with no statistically significant difference ( $\mathrm{p}$ value $=0.384$ ). On the other hand, a significant difference of the mean scores was observed between the both groups after one and two months of implementation of an educational intervention. The mean scores of satisfaction, orgasm, and desire subscales were significantly higher in the study group compared with the control group $(\mathrm{p} \leq 0.001)$. Whereas, the mean score of the pelvic problem interference subscale was significantly lower in the study group compared with the control group $(\mathrm{p} \leq 0.001)$.

Table (5) reveals a highly statistically significant negative correlation between total EHP-30 and SHOW-Q scores between both groups before, after one and two months of the implementation of educational intervention $(\mathrm{P} \leq 0.001)$. 
Table 1. Distribution of the studied women in study and control groups according to demographic characteristics $(\mathrm{n}=138)$

\begin{tabular}{|c|c|c|c|c|c|c|}
\hline \multirow{2}{*}{$\overbrace{\text { Variables }}$ Groups } & \multicolumn{2}{|c|}{ 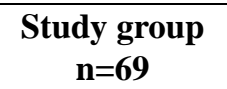 } & \multicolumn{2}{|c|}{$\begin{array}{c}\text { Control group } \\
n=69\end{array}$} & \multirow[t]{2}{*}{$X^{2}$} & \multirow[t]{2}{*}{$P$-value } \\
\hline & No & $\%$ & No & $\%$ & & \\
\hline \multicolumn{7}{|l|}{ Age (years) } \\
\hline$<30$ & 13 & 18.8 & 20 & 29.0 & 1.952 & $0.162^{\mathrm{ns}}$ \\
\hline$\geq 30$ & 56 & 81.2 & 49 & 71.0 & & \\
\hline Range & \multicolumn{2}{|c|}{$27-41$} & \multicolumn{2}{|c|}{$26-45$} & & \\
\hline Mean \pm SD & \multicolumn{2}{|c|}{$32.29 \pm 2.58$} & \multicolumn{2}{|c|}{$31.54 \pm 2.91$} & $t=1.606$ & $0.111^{\mathrm{ns}}$ \\
\hline \multicolumn{7}{|l|}{ Educational level } \\
\hline Primary education & 2 & 2.9 & 4 & 5.8 & $1.582^{€}$ & $0.453^{\mathrm{ns}}$ \\
\hline Secondary education & 39 & 56.5 & 43 & 62.3 & & \\
\hline University education & 28 & 40.6 & 22 & 31.9 & & \\
\hline \multicolumn{7}{|l|}{ Residence } \\
\hline Urban & 11 & 15.9 & 16 & 23.2 & 1.151 & $0.283^{\mathrm{ns}}$ \\
\hline Rural & 58 & 84.1 & 53 & 76.8 & & \\
\hline \multicolumn{7}{|l|}{ Occupation } \\
\hline Working & 31 & 44.9 & 22 & 31.9 & 2.481 & $0.115^{\mathrm{ns}}$ \\
\hline Housewife & 38 & 55.1 & 47 & 68.1 & & \\
\hline \multicolumn{7}{|l|}{ Monthly income } \\
\hline Enough & 13 & 18.8 & 9 & 13.0 & 0.865 & $0.352^{\mathrm{ns}}$ \\
\hline Not enough & 56 & 81.2 & 60 & 87.0 & & \\
\hline
\end{tabular}

Table 2. Distribution of the studied women in study and control groups according to obstetrics history and data about endometriosis $(\mathrm{n}=138)$

\begin{tabular}{|c|c|c|c|c|c|c|}
\hline \multirow[t]{2}{*}{ Groups } & \multicolumn{2}{|c|}{$\begin{array}{c}\begin{array}{c}\text { Study group } \\
n=69\end{array} \\
\text { a }\end{array}$} & \multicolumn{2}{|c|}{$\begin{array}{c}\text { Control group } \\
n=69\end{array}$} & \multirow[t]{2}{*}{$X^{2}$} & \multirow[t]{2}{*}{ P-value } \\
\hline & No & $\%$ & No & $\%$ & & \\
\hline \multicolumn{7}{|l|}{ Gravidity } \\
\hline None & 49 & 71.0 & 46 & 66.7 & \multirow[t]{3}{*}{1.904} & \multirow[t]{3}{*}{$0.386^{\mathrm{ns}}$} \\
\hline One & 15 & 21.8 & 13 & 18.8 & & \\
\hline Two & 5 & 7.2 & 10 & 14.5 & & \\
\hline \multicolumn{7}{|l|}{ Parity } \\
\hline None & 52 & 75.4 & 48 & 69.6 & \multirow[t]{3}{*}{$3.314^{€}$} & \multirow[t]{3}{*}{$0.191^{\mathrm{ns}}$} \\
\hline One & 14 & 20.3 & 12 & 17.4 & & \\
\hline Two & 3 & 4.3 & 9 & 13.0 & & \\
\hline \multicolumn{7}{|l|}{ Type of endometriosis } \\
\hline Ovarian & 53 & 76.8 & 57 & 82.6 & \multirow[t]{3}{*}{0.717} & \multirow[t]{2}{*}{$0.397^{\mathrm{ns}}$} \\
\hline Rectovaginal & 16 & 23.2 & 12 & 17.4 & & \\
\hline \multicolumn{6}{|c|}{ Stage of endometriosis } & \\
\hline Stage I & 55 & 79.7 & 50 & 72.5 & \multirow[t]{3}{*}{$1.766^{\epsilon}$} & \multirow[t]{3}{*}{$0.414^{\mathrm{ns}}$} \\
\hline Stage I & 10 & 14.5 & 16 & 23.2 & & \\
\hline Stage II & 4 & 5.8 & 3 & 4.3 & & \\
\hline \multicolumn{7}{|c|}{ Duration of endometriosis (years) } \\
\hline Range & \multirow{2}{*}{\multicolumn{2}{|c|}{$\begin{array}{c}3-5 \\
3.93 \pm 0.73\end{array}$}} & \multicolumn{2}{|c|}{$\begin{array}{l}2-5 \\
2-505\end{array}$} & & \\
\hline Mean \pm SD & & & & .95 & $\mathrm{t}=1.401$ & $0.163^{\mathrm{ns}}$ \\
\hline
\end{tabular}




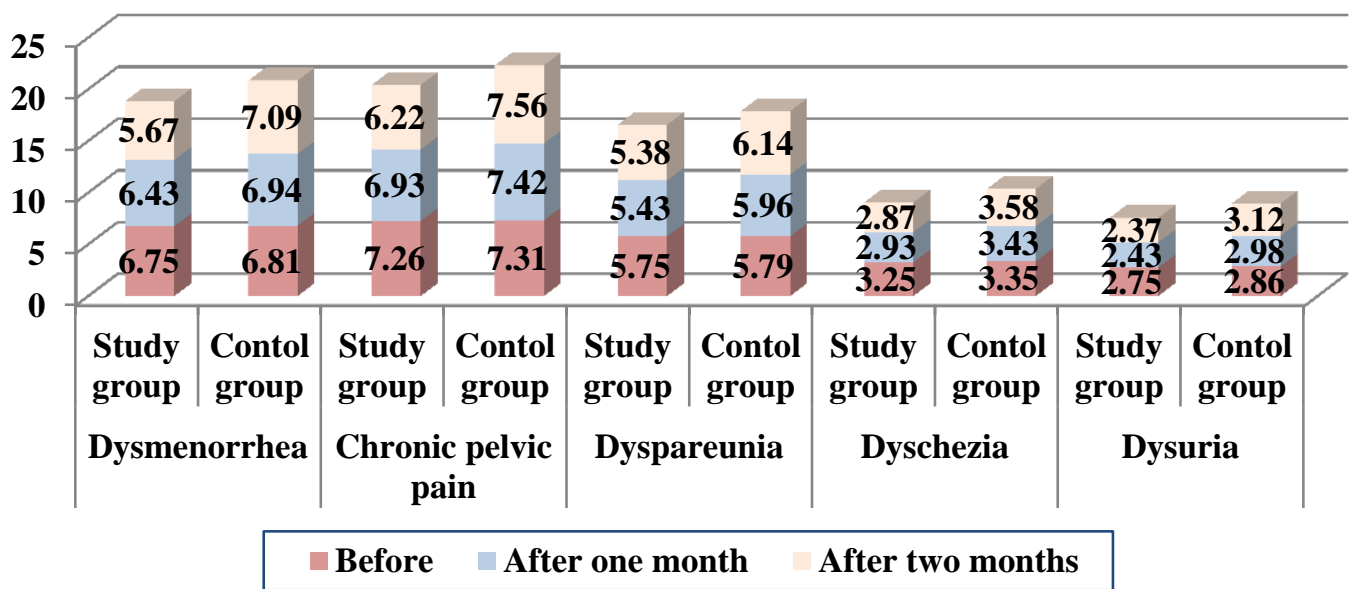

Figure 1. Comparison of the mean scores of intensity of endometriosis-related pain symptoms between study and control groups before, after one and two months of the implementation of educational intervention $(n=138)$

Table 3. Comparison of mean scores of EHP-30 between study and control groups before, after one and two months of the implementation of educational intervention $(n=138)$

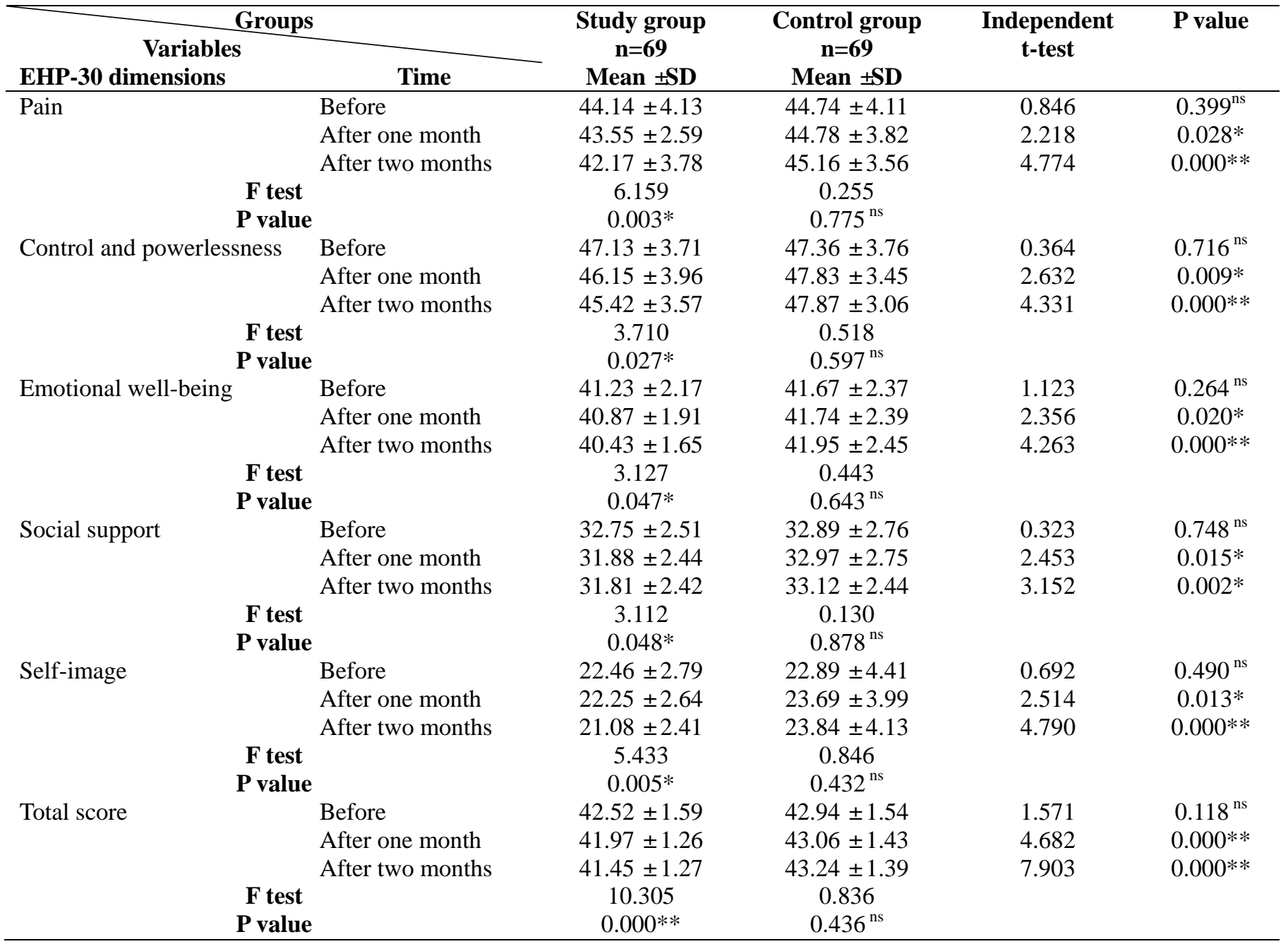

\footnotetext{
*A statistically significant difference $(\mathrm{P} \leq 0.05)$
}

**A highly statistically significant difference $(\mathrm{P} \leq 0.001)$

${ }^{\mathrm{ns}}$ no statistically significant difference $(\mathrm{p}>0.05)$ 
Table 4. Comparison of the mean scores of sexual health outcomes questionnaire between study and control groups before, after one and two months of the implementation of educational intervention $(n=138)$

\begin{tabular}{|c|c|c|c|c|c|}
\hline & Groups & Study group & Control group & Independent & $P$ value \\
\hline $\begin{array}{l}\text { SHOW-Q } \\
\text { Subscales }\end{array}$ & Time & Mean \pm SD & Mean \pm SD & & \\
\hline Satisfaction & Before & $37.81 \pm 3.00$ & $37.48 \pm 3.40$ & 0.610 & $0.543^{\mathrm{ns}}$ \\
\hline & After one month & $51.88 \pm 8.35$ & $37.27 \pm 2.97$ & 13.687 & $0.000 * *$ \\
\hline & After two months & $51.93 \pm 10.74$ & $37.12 \pm 2.96$ & 11.044 & $0.000 * *$ \\
\hline & F test & 61.831 & 0.220 & & \\
\hline & $P$ value & $0.000 * *$ & $0.802^{\mathrm{ns}}$ & & \\
\hline Orgasm & Before & $56.98 \pm 12.90$ & $59.83 \pm 11.92$ & 1.343 & $0.181^{\mathrm{ns}}$ \\
\hline & After one month & $63.62 \pm 2.35$ & $57.58 \pm 12.55$ & 3.932 & $0.000 * *$ \\
\hline & After two months & $65.89 \pm 8.68$ & $56.64 \pm 12.94$ & 4.936 & $0.000 * *$ \\
\hline & F test & 19.214 & 1.829 & & \\
\hline & $P$ value & $0.000 * *$ & $0.165^{\mathrm{ns}}$ & & \\
\hline Desire & Before & $55.42 \pm 4.69$ & $54.72 \pm 5.00$ & 0.843 & $0.401^{\mathrm{ns}}$ \\
\hline & After one month & $57.22 \pm 5.03$ & $53.86 \pm 6.02$ & 3.562 & $0.001^{*}$ \\
\hline & After two months & $59.46 \pm 8.48$ & $53.62 \pm 6.03$ & 4.662 & $0.000 * *$ \\
\hline & F test & 9.803 & 0.960 & & \\
\hline & $P$ value & $0.000 * *$ & $0.385^{\mathrm{ns}}$ & & \\
\hline Pelvic problem & Before & $60.23 \pm 3.52$ & $60.62 \pm 2.43$ & 0.760 & $0.448^{\mathrm{ns}}$ \\
\hline interference & After one month & $57.43 \pm 3.32$ & $60.74 \pm 2.29$ & 6.793 & $0.000 * *$ \\
\hline & After two months & $55.33 \pm 9.51$ & $61.81 \pm 4.05$ & 5.207 & $0.000 * *$ \\
\hline & F test & 11.625 & 2.938 & & \\
\hline & $P$ value & $0.000 * *$ & $0.056^{\mathrm{ns}}$ & & \\
\hline Total score & Before & $52.58 \pm 4.45$ & $53.19 \pm 3.76$ & 0.873 & $0.384^{\mathrm{ns}}$ \\
\hline & After one month & $57.01 \pm 2.81$ & $52.82 \pm 4.02$ & 7.099 & $0.000 * *$ \\
\hline & After two months & $57.15 \pm 6.56$ & $52.68 \pm 4.05$ & 4.550 & $0.000 * *$ \\
\hline & F test & 22.724 & 0.407 & & \\
\hline & $P$ value & $0.000 * *$ & $0.656^{\mathrm{ns}}$ & & \\
\hline
\end{tabular}

Table 5. Correlation coefficient between total EHP-30 and SHOW-Q scores between study and control groups before, after one and two months of the implementation of educational intervention $(n=138)$

\begin{tabular}{lllccc}
\hline & \multirow{2}{*}{ Variables } & \multicolumn{3}{c}{ Total EHP-30 score } \\
& & \multicolumn{2}{c}{$\begin{array}{c}\text { Study group } \\
\mathbf{n = 6 9}\end{array}$} & \multicolumn{2}{c}{$\begin{array}{c}\text { Control group } \\
\mathbf{n = 6 9}\end{array}$} \\
& & $\mathbf{r}$ & $\mathbf{p}$ & $\mathbf{r}$ & $\mathbf{p}$ \\
\hline Total SHOW-Q & Before & -0.513 & $0.000^{* *}$ & -0.476 & $0.000^{* *}$ \\
score & After one month & -0.564 & $0.000^{* *}$ & -0.482 & $0.000^{* *}$ \\
& After two months & -0.541 & $0.000^{* *}$ & -0.496 & $0.000^{* *}$ \\
\hline
\end{tabular}

$* *$ A highly statistically significant difference $(\mathrm{P} \leq 0.001)$

\section{Discussion}

Endometriosis is associated with debilitating pelvic pain, impairment of psychological as well as social functioning and reduction in quality of life as well as sexual satisfaction (Tripoli et al. 2011). Outlining wellbeing training programs and education about endometriosis and its related predisposing factor ought to be a need to guarantee early determination of the disease (Mamdouh et al. 2011). This study aimed to investigate the effect of an educational intervention on quality of life and sexual function in women with endometriosis.

The finding of the current study revealed that the mean age of the study and control groups was $32.29 \pm 2.58$ (range: 27 to 41 years) and $31.54 \pm 2.91$ years (range: 26 to 45 years) respectively. This was nearly congruent with Rasheed et al. (2010) who found no statistically significant difference between the two groups as regards the mean 
age (29.2 \pm 4.5 vs. $31.7 \pm 3.8 ; \mathrm{P}=0.2)$. In contrast, Mishra et al. (2016) reported that the mean age of women was $28.51 \pm 5.15$ years. Also El-Maraghy et al. (2017) reported that the mean age of the women with endometriosis was 37.3 years (range: 24 to 45 years). Less than two thirds of both groups had a secondary education. More than three quarters of both groups live in rural areas. In relation to occupation, more than half of the study and control groups were housewives. More than three quarters of both groups had no enough monthly income. There was no statistically significant difference between both groups regarding demographic characteristics. This means that both groups were homogenous.

Furthermore, more than two thirds of both groups were nulligravidae and nulliparae. Regarding type of endometriosis, more than three quarters of both groups had ovarian endometriosis and stage I endometriosis. This was in the same line with Facchin et al. (2015) who found that overall $70 \%$ of the women $(n=77)$ had ovarian endometriosis, and $17.3 \%(\mathrm{n}=19)$ had rectovaginal endometriosis. The mean duration of endometriosis of the study and control groups was $3.93 \pm 0.73$ and $3.72 \pm 0.95$ years respectively, with no statistically significant difference between both groups regarding obstetrics history and data about endometriosis.

The findings of the present study illustrated that mean intensity score of endometriosis-related pain symptoms (dysmenorrhea, chronic pelvic pain, dyspareunia, dyschezia and dysuria) were matched in both groups before implementation of educational intervention. The intensity of dysmenorrhea, chronic pelvic pain, and dyspareunia were severe in the both groups. This was in accordance with Acien and Velasco (2013) who pointed out that the most common symptoms of endometriosis are dysmenorrhea (during and at the end of menstruation), chronic pelvic pain, dyspareunia, and infertility in $30 \%$ of the cases. The intensity of symptoms may range from mild to severe, but the level of pain does not always relate to the severity of the disease. Also, Touboul et al. (2013) found that the most intense symptoms were dysmenorrhea (7.1/10). Gupta et al. (2015) demonstrate that dyspareunia as a common complaint in women with endometriosis.

Meanwhile, a statistically significant decrease in the intensity of endometriosis-related pain symptoms occurred in the study group compared with the control group after one month and two months of educational intervention implementation. This might be due to women interested with contents of educational intervention i.e a healthy diet, exercise and non-pharmacological management strategies that help them to acquire knowledge of how to adapt with endometriosis for overcoming the symptoms. This result was consistent with Moradi et al. (2014) pointed out that lifestyle changes such as exercise, diet and sleep are used for the management of endometriosis. In addition, Ghonemy and El Sharkawy (2017) showed a significant reduction of endometriosis related pain; mean pain score pre and three months after completion of health education $7.44 \pm 1.45$ and $5.7 \pm 1.34$ respectively $(\mathrm{t}=10.798, \mathrm{p}<0.001)$.

The findings of the current study revealed that, before implementation of educational intervention, the mean scores of total EHP-30 and its dimensions revealed impairment of the quality of life in the both groups with no statistically significant difference. This could be due to women with endometriosis suffer painful symptoms that impact quality of life. Moreover, many women with endometriosis reported lack of control and restrict their lives and feel powerless, with impaired social functioning.

These findings were supported by Nnoaham et al. (2011) who found that women with endometriosis had a significant reduction in the quality of life compared to women with other gynaecological problems. Bernuit et al. (2011) found that $67 \%$ of women reported that endometriosis had a negative impact on QoL, $36 \%$ said it affected relationships with family. Vercellin et al. (2013) reported that half women reported continued suffering from dyspareunia with significant effect on quality of life. De Graaff et al. (2013) reported that endometriosis leads to impaired quality of life. Also, Stull et al. (2014) reported that existence of symptomatic endometriosis has physical, mental and adverse impact on the social well-being and thus has a negative impact on health-related quality of life. Melis et al. (2015) added that women with endometriosis experience significantly poorer QOL and lower body image compared to health controls.

However, statistically significant differences of the mean scores were observed between both groups after one and two months of implementation of educational intervention. The mean total score of EHP-30 was significantly lowered in the study group compared with the control group, which indicates better quality of life in the study group. Such significant differences also existed in the five dimensions of EHP-30; pain, control and powerlessness, emotional well-being, social support, and self-image. This improvement might be related to the effect of educational intervention sessions that were given to women to how cope with the endometriosis and make informed decisions regarding managing and overcoming its painful symptoms. Additionally, an educational booklet about endometriosis provided to the study group. 
This was supported by Moradi et al. (2014) who pointed out that the impact of endometriosis is worsened by a lack of understanding of the disease. Better understanding of the long term and wide ranging impact of endometriosis on women's lives at different life stages could benefit in reducing the negative impact of endometriosis and improving women's life experiences. Thomas and Natarajan (2013) concluded that dietary factors play an important role in prevention and progression of endometriosis and is imperative as a treatment modality in improving the quality of life of women suffering from endometriosis.

Concerning sexual function, the findings of the present study showed that, the mean scores of total SHOW-Q and its subscales indicated worse sexual functioning in both groups were slightly similar with no statistically significant difference before implementation of educational intervention. This might be related to women's endometriosis symptoms especially dyspareunia are strongly associated with a marked impairment of sexual function in women.

This was in consistent with Setala et al. (2012) who found that chronic pelvic pain due to endometriosis reduced sexual aspects of life and satisfaction. De Graaff et al. (2013) displayed that women with endometriosis reported having less sex and more frequent interruption of intercourse due to pain. Montanari et al. (2013) found that the mean values of the SHOW-Q showed poor sexual function (mean SHOW-Q total score $56.38 \pm 22.74$ ). Satisfaction was the dimension most affected (mean satisfaction score $55.66 \pm 34.55$ ), followed by orgasm (mean orgasm score $56.90 \pm 33.77$ ) and revealed sexual satisfaction is seriously compromised in women with endometriosis.

Furthermore, Di Donato et al. (2013) reported that the mean values of SHOW-Q $56.4 \pm 21.1$ showed an impairment of sexual function and emphasized that pelvic symptoms can cause impairment of all aspects of sexual functioning such as satisfaction, orgasm, and desire. Fourquet et al. (2011) found that $71 \%$ of women reported that endometriosis negatively affected their sexual lives. Chene et al. (2012) reported that the quality of sexual life was affected in both women with minimal and severe endometriosis. Melis et al. 2015 emphasized that endometriosis women experience a sense of guilt towards husbands, lower feelings of femininity, and alteration of body image, which in turn, worsen sexual dysfunction.

On the other hand, a significant difference of the mean scores between both groups was reported after one and two months of educational intervention implementation. The mean scores of satisfaction, orgasm, and desire subscales were significantly higher in the study group compared with the control group. Whereas, the mean score of the pelvic problem interference subscale was significantly lower in the study group compared with the control group which indicated better sexual functioning. This might be attributed to the educational intervention of health teaching to help women with endometriosis to cope with this condition. In addition, psychological support offered to women help to express complaints, and concerns about therapy and sexual problems.

These findings were congruent with Roth et al. 2011 and Culley et al. (2013) who emphasized that the management of post-diagnostic healthcare needs to be more holistic. This should be clarified by understanding of the multidimensional impact of endometriosis and supported by a biopsychosocial approach that includes; emotional support, stress reduction, social support, coping strategies, control of pain, psychosexual therapy and focus on quality of life and sexual issues.

Furthermore, the finding of the current study displayed a highly statistically significant negative correlation between total EHP-30 and SHOW-Q score between both groups before, after one and two months of the implementation of educational intervention This is might be attribute to interrelation limitations due to endometriosis-related pain symptoms, which may compromise relationships with husband and sexuality impairment due to dyspareunia. This was agrees with Montanari et al. (2013) who found that sexual dysfunction and deterioration of QOL seem to be correlated.

\section{Conclusion}

It was evident from the study findings that the educational intervention about endometriosis has a significant effect on the improvement of women's quality of life and sexual function; quality of life was better in the study group compared with the control group, such significantly improvement in the EHP-30 dimensions of pain, control and powerlessness, emotional well-being, social support and self-image. Also, sexual function was significantly higher in the study group compared with the control group. Therefore, the research hypothesis was supported. 


\section{Recommendations}

Based on the findings of the current study, the following recommendations are suggested:

- Provide health educational program for women with endometriosis to improve quality of life as well as sexual function.

- Educational booklets should be available for women with endometriosis to increase their awareness regarding non pharmacological measures to relieve endometriosis-related pain symptoms.

- Regular follow up of women with endometriosis to evaluate health related quality of life and sexual function to detect any health problems early.

- Replication of the study using a probability sample in different hospital settings is recommended for generalization of results.

Further studies

- Study the effect of training programs on nurses' knowledge and attitude about endometriosis.

- Provide health teaching programs to raise awareness of endometriosis symptoms among undiagnosed women to ensure early diagnosis of the disease.

- Assess prevalence of endometriosis among adolescent girls with severe dysmenorrhea.

\section{References}

Acien, P., \& Velasco, I. (2013). Endometriosis: A disease that remains enigmatic. ISRN Obstetrics and Gynecology, ID 242149, 12.

Bedaiwy, M.A., \& Liu, J. (2010). Long-term management of endometriosis: medical therapy and treatment of infertility. Sex Reprod Menopause, 8, 10-14.

Begum, T., \& Chowdhury. S.R. (2013). A etiology and pathogenesis of endometriosis: a review. Mymensigh Med, $1,218-221$.

Bernuit, D., Ebert, A.D., Halis, G., Strothmann, A., Gerlinger, C., Geppert, K., \& Faustmann, T. (2011). Female perspectives on endometriosis: findings from the uterine bleeding and pain women's research study. $J$ Endometriosis, 2, 73-85. https://doi.org/10.5301/JE.2011.8525

Chene, G., Jaffeux, P., Lasnier, C., Cuvelier, B.A., Tamburro, S., Matsuzaki, S., ... Canis, M. (2012). Quality of life of women with endometriosis: comparison between epiphenomenon and severe disease. $J$ Endometriosis, 2, 77-84. https://doi.org/10.5301/JE.2012.9408

Culley, L., Law, C., Hudson, N., Mitchell, H., Denny, E., Mitchell, H., ... Raine-Fenning, N. (2013). The social and psychological impact of endometriosis on women's lives: a critical narrative review. Human Reproduction Update, 19(6), 625-639. https://doi.org/10.1093/humupd/dmt027

De Graaff, A.A., D’Hooghe, T.M., Dunselman, G.A., Dirksen, C.D., Hummelshoj, L., \& Simoens, S. (2013). The significant effect of endometriosis on physical, mental and social wellbeing: results from an international cross-sectional survey. Hum Reprod, 28(10), 2677-2685. https://doi.org/10.1093/humrep/det284

Di Donato, N., Montanari, G., Benfenati, A., Leonardi, D., Bertoldo, V., Monti, Gi., .. Seracchioli, R. (2013). The impact of socioeconomic and anamnestic characteristics on quality of life and sexual function in women with endometriosis. $J$ Endometr Pelvic Pain Disord, 5(4), 159-165. https://doi.org/10.5301/je.5000168

Dunselman, G.A., Vermeulen, N., Becker, C., Calhaz-Jorge, C., D’Hooghe, T., De Bie, B., ... Nelen, W. (2014). European Society of Human Reproduction and Embryology. ESHRE guideline: management of women with endometriosis. Hum Reprod, 29, 400-412. https://doi.org/10.1093/humrep/det457

El-Maraghy, M., Labib, K., El-Din, W.S., \& Ahmed, A.B. (2017). The impact of endometriosis symptoms on health related quality of life and work productivity in Egypt. Austin J Obstet Gynecol, 4(3), 1078-1086. https://doi.org/10.26420/austinjobstetgynecol.2017.1078

Facchin, F., Barbara, G., Saita, E., Mosconi, P., Roberto, A., Fedele, L., \& Vercellini, P. (2015). Impact of endometriosis on quality of life and mental health: pelvic pain makes the difference. J Psychosom Obstet Gynaecol, 36(4), 135-141. https://doi.org/10.3109/0167482X.2015.1074173

Ferreira, A.L.L., Bessaa, M.M.M., Drezett, J., \& Abreub, L.C.D. (2016). Quality of life of the woman carrier of endometriosis: systematized review. Peprodclim, 3, 48-54. https://doi.org/10.1016/j.recli.2015.12.002 
Fourquet, J., Baez, L., Figueroa, M., Iriarte, R.I., \& Flores, I. (2011). Quantification of the impact of endometriosis symptoms on health related quality of life and work productivity. Fertil Steril, 96, 107-112. https://doi.org/10.1016/j.fertnstert.2011.04.095

Ghonemy, G.E., \& El Sharkawy, N.B. (2017). Impact of changing lifestyle on endometriosis related pain. IOSR Journal of Nursing and Health Science, 6(2), 120-129. https://doi.org/10.9790/1959-060205120129

Giuliani, M., Cosmia, V., Pierleonia, L., Recinea, A., Pieronia, M., Ticino, A.,... Simonelli C. (2016). Quality of life and sexual satisfaction in women suffering from endometriosis: An Italian preliminary study. Sexologies, 25, e12-e19. https://doi.org/10.1016/j.sexol.2015.03.004

Greene, A.D., Lang, S.A., Kendziorski, J.A., Sroga-Rios, J.M., Herzog, T.J., \& Burns, K.A. (2016). Endometriosis: where are we and where are we going? Reproduction, 152(3), R63-R78. https://doi.org/10.1530/REP-16-0052

Gupta, S., Harlev, A., Agarwal, A., Reynolds, N., Beydola, T., \& Haroun, N. (2015). Endometriosis: Impact on Patient Quality of Life. In Endometriosis a comprehensive update (pp.75-78). Springer. https://doi.org/10.1007/978-3-319-18308-4_8

Jones, G., Kennedy, S., Barnard, A., Wong, J., \& Jenkinson, C. (2001). Development of an endometriosis quality of life instrument: The Endometriosis Health Profile-30. Obstet Gynecol, 98(2), 258-264. https://doi.org/10.1097/00006250-200108000-00014

Kish, L. (1965). Survey sampling. New York John Wiley and Sons, Inc, 664.

Kong, S., Zhang, Y.H., Liu, C.F., Tsui, I., Guo, Y., Ai, B.B., ... Han, F.J. (2014). The complementary and alternative medicine for endometriosis: A review of utilization and mechanism. Evidence-Based Complementary and Alternative Medicine, 1-16. https://doi.org/10.1155/2014/146383

Lagana, A.S., Vitale, S.G., Salmeri, F.M., Triolo, O., Ban Frangez, H., Vrtacnik-Bokal, E., ... Sofo, V. (2017). A novel, evidence-based, unifying theory for the pathogenesis of endometriosis. Med Hypotheses, 103, 10-20. https://doi.org/10.1016/j.mehy.2017.03.032

Langer, A., Meleis, A., Knaul, F.M., Atun, R., Aran, M., Arreola-Ornelas, H., ... Frenk, J. (2015). Women and Health: the key for sustainable development. Lancet, 386, 1165-1210. https://doi.org/10.1016/S0140-6736(15)60497-4

Learman, L.A., Huang, A.J., Nakagawa, S., et al. (2008). Development and validation of a sexual functioning measure for use in diverse women's health outcome studies. Am J Obstet Gynecol, 198, 710.e1-e8; discussion 710.e8-e9.

Mamdouh, H.M., Mortada, M.M., Kharboush, I.F., \& Abd-Elateef, H.A. (2011). Epidemiologic determinants of endometriosis among Egyptian women: a hospital-based case-control study. J Egypt Public Health Assoc, 86(1-2), 21-26. https://doi.org/10.1097/01.EPX.0000395322.91912.56

Mao, A.J., \& Anastasi, J.K. (2010). Diagnosis and management of endometriosis: the role of the advanced practice nurse in primary care. $J$ Am Acad Nurse Pract., 22(2), 109-116. https://doi.org/10.1111/j.1745-7599.2009.00475.x

McKinney, E.S., James, S.R., Murray, S.S., Nelson, K., \& Ashwill, J. (2013). Maternal-Child Nursing (4th ed.). Saunders, 777.

Melis, I., Litta, P., Nappi, L., Agus, M., Melis, G.B., \& Angioni, S. (2015). Sexual function in women with deep endometriosis: Correlation with quality of life, intensity of pain, depression, anxiety, and body image. International Journal of Sexual Health, 27(2), 175-185. https://doi.org/10.1080/19317611.2014.952394

Mishra, V., Nanda, S., Gandhi, K., Aggarwal, R., Choudhary, S., \& Gondhali, R. (2016). Female sexual dysfunction in patients with endometriosis: Indian scenario. J Hum Reprod Sci., 9(4), 250-253. https://doi.org/10.4103/0974-1208.197687

Montanari, G., Di Donato, N., Benfenati, A., Giovanardi, G., Zannoni, L., Vicenzi, C., \& Seracchioli R. (2013). Women with deep infiltrating endometriosis: sexual satisfaction, desire, orgasm, and pelvic problem interference with sex. J Sex Med, 10, 1559-1566. https://doi.org/10.1111/jsm.12133

Moradi, M., Parker, M., Sneddon, A., Lopez, V., \& Ellwood, D. (2014). Impact of endometriosis on women's lives: a qualitative study. BMC Women's Health, 14, 123. https://doi.org/10.1186/1472-6874-14-123 
Nnoaham, K.E., Hummelshojc, L., Webster, P., d'Hooghe, T., de Cicco Nardone, F., de Cicco Nardone, C., ... Zondervan, K.T. (2011). Impact of endometriosis on quality of life and work productivity: a multicenter study across 10 countries. Fertility and Sterility, 96(2), 366-373. https://doi.org/10.1016/j.fertnstert.2011.05.090

Peloquin, K., Brassard, A., Delisle, G., \& Bedard, M.M. (2013). Integrating the attachment, caregiving, and sexual systems into the understanding of sexual satisfaction. Can J Behav Sci, 45(3), 185-195. https://doi.org/10.1037/a0033514

Pluchino, N., Wenger, J., Petignat, P., Tal, R., Bolmont, M., Taylor, H., \& Bianchi-Demicheli, F. (2016). Sexual function in endometriosis patients and their partners: effect of the disease and consequences of treatment. Human Reproduction Update, 22(6), 762-774. https://doi.org/10.1093/humupd/dmw031

Posadzka, E., Jach, R., Pityński, K., \& Jablonski, M. (2015). Treatment efficacy for pain complaints in women with endometriosis of the lesser pelvis after laparoscopic electro ablation vs. CO2 laser ablation, Lasers Med Sci., 30(1), 147-152. https://doi.org/10.1007/s10103-014-1630-4

Rasheed, K., Atta, H., Taha, T.F., Azmy, O., Sabry, D., Selim, M., \& Anwar, M. (2010). A novel endometriosis inducing factor in women with endometriosis. Journal of Stem cells and Regenerative medicine, 3(6), 157-164.

Roth, R.S., Punch, M.R., \& Bachman, J.E. (2011). Psychological factors in chronic pelvic pain due to endometriosis: a comparative study. Gynecol Obstet Inves, (1), 15-19.

Setala, M., Harkki, P., Matomaki, J., Makinen, J., \& Kossi, J. (2012). Sexual functioning, quality of life and pelvic pain 12 months after endometriosis surgery including vaginal resection. Acta Obstet Gynecol Scand., 91, 692-698. https://doi.org/10.1111/j.1600-0412.2012.01394.x

Silva, C.N., Costa, P., Martins, C., Barat, S., Alho, C., Jorge, C.C., \& Osorio, F. (2015). Validation of the Portuguese Version of EHP-30 (The Endometriosis Health Profile-30). Acta Med Port, 28, 347-356. https://doi.org/10.20344/amp.5778

Stull, D.E., Wasiak, R., Kreif, N., Raluy, M., Colligs, A., Seitz, C., \& Gerlinger, C. (2014). Validation of the SF-36 in patients with endometriosis. Qual Life Res. 23, 103-117. https://doi.org/10.1007/s11136-013-0442-5

Thomas, D.S., \& Natarajan, J.R. (2013). Diet-a new approach to treating endometriosis- what is the evidence? IOSR Journal of Nursing and Health Science, 1(5), 4-11. https://doi.org/10.9790/1959-0150411

Touboul, C., Amate, P., Ballester, M., Bazot, M., Fauconnier, A., \& Dara, E. (2013). Quality of Life Assessment Using EuroQOL EQ-5D Questionnaire in Patients with Deep Infiltrating Endometriosis: The Relation with Symptoms and Locations. International Journal of Chronic Diseases, 7.

Tripoli, T.M., Sato, H., Sartori, M.G., de Araujo, F.F., Girao, M.J., \& Schor, E. (2011). Evaluation of quality of life and sexual satisfaction in women suffering from chronic pelvic pain with or without endometriosis. Journal for Sexual Medicine, 2, 497-503. https://doi.org/10.1111/j.1743-6109.2010.01976.x

Vercellini, P., Frattaruolo, M.P., Somigliana, E., Jones, G.L., Consonni, D., Alberico, D., \& Fedele, L. (2013). Surgical versus low-dose progestin treatment for endometriosis associated severe deep dyspareunia II: effect on sexual functioning, psychological status and health-related quality of life. Human Reprod, 28, 1221-1230. https://doi.org/10.1093/humrep/det041

World Health Organization. (2010). Developing sexual health programs. A framework for action. Retrieved from http://www.who.int/reproductivehealth/publications/sexual health/rhr hrp 1022/en/

\section{Copyrights}

Copyright for this article is retained by the author(s), with first publication rights granted to the journal.

This is an open-access article distributed under the terms and conditions of the Creative Commons Attribution license (http://creativecommons.org/licenses/by/4.0/). 